\title{
ANÁLISE DE AGRUPAMENTO DA TEMPERATURA DO AR NO SUL DO BRASIL ENTRE 1961-2011
}

\author{
Flávia Venturini Rosso ${ }^{1}$, Nathalie Tissot Boiaski, Simone Erotildes Teleginski Ferraz \\ Departamento de Física, Universidade Federal de Santa Maria \\ 11flavia.rosso@hotmail.com
}

\begin{abstract}
RESUMO
A região sul do Brasil possui uma economia baseada nos setores pecuário e agrícola que, por sua vez, dependem da variabilidade de elementos meteorológicos como a precipitação e a temperatura. Neste estudo, foi realizada uma análise climatológica da temperatura do ar no sul do país para o período de 1961 a 2011, utilizando a análise de agrupamento e, assim, provendo informações sobre a variabilidade espacial da temperatura na região.
\end{abstract}

\begin{abstract}
The economy in the southern Brazil is based on agriculture and livestock sectors which, in turn, depend on the meteorological parameters variability, such as precipitation and temperature. In this study was performed a climatological analysis of the air temperature in the southern Brazil during 1961-2011, using the cluster analysis and thereby providing information about the temperature spatial variability on the region.
\end{abstract}

\section{INTRODUÇÃO}

Em vários setores da sociedade, como por exemplo, agropecuária, comércio e turismo, o conhecimento da variabilidade da temperatura é determinante para o planejamento das atividades de tais setores. Na região sul destaca-se algumas atividades com papel econômico no país como: $45,51 \%$ da plantação de soja, $42,7 \%$ da produção de cereais e leguminosas (IBGE, 2010) e 43,70\% da produção de suínos (IBGE, 2005). A análise de agrupamento tem importância no zoneamento agrícola no sentido de que o conhecimento detalhado de regiões homogêneas serve de base, por exemplo, para a escolha das culturas de menor risco a serem plantadas, bem como o período mais favorável para o plantio (Filho et al., 2005).

Desta forma, o objetivo deste trabalho é investigar a variabilidade espacial da temperatura do ar na região Sul do Brasil, por meio da análise de agrupamento.

\section{DADOS E METODOLOGIA}

Neste trabalho foram utilizados dados diários de temperatura média do ar de 28 estações meteorológicas, disponibilizados pelo Instituto Nacional de Meteorologia (INMET), para o período de 1961 a 2011. Primeiramente, foi determinada a porcentagem de dados faltantes em cada estação. Definiu-se excluir do trabalho as estações que tivessem mais do que $25 \%$ de falhas, resultando em 22 estações a serem trabalhadas, as quais estão representadas na Figura 1. A análise a seguir foi realizada no período concomitante de dados entre as estações, eliminando-se dados espúrios.

Para determinar as regiões homogêneas, foi aplicada a técnica estatística multivariada da análise de agrupamento hierárquico, usando a distância euclidiana como função de 
agrupamento. Assim, num espaço P-dimensional, a distância entre dois pontos $x_{i}$ e $x_{j}$ é dada por:

$$
d_{i j}=\left\|x_{i}-x_{j}\right\|=\left[\sum_{k=1}^{P}\left(x_{i, k}-x_{j, k}\right)^{2}\right]^{\frac{1}{2}}
$$

O método de agrupamento utilizado foi o da ligação-média. Segundo Wilks (2006), este método define a distância média entre todos possíveis pares de pontos nos dois grupos a serem comparados. A escolha por este método é devido ao seu melhor funcionamento em relação ao agrupamento das regiões homogêneas.

Por fim, foi gerado o dendrograma da análise de agrupamento, mostrado na Figura 2.

\section{RESULTADOS E DISCUSSÃO}

Pelo dendrograma então, formou-se seis regiões homogêneas, conforme mostra a Figura 3. São Joaquim não foi agrupada com nenhuma estação.

Assim, com as regiões homogêneas definidas, pode ser feita a caracterização de cada uma, de acordo com a Figura 4. Na região 1 (pontos azuis, Fig. 3), a amplitude térmica é de aproximadamente $28^{\circ} \mathrm{C}$, com mínimo (máximo) valor de temperatura média diária em torno de $5^{\circ} \mathrm{C}\left(33^{\circ} \mathrm{C}\right)$ e mediana de $19^{\circ} \mathrm{C}$. O valor mínimo (máximo) da temperatura média diária na região 2 (pontos laranjas, Fig. 3), é em torno de $3^{\circ} \mathrm{C}\left(33^{\circ} \mathrm{C}\right)$, e mediana de $19^{\circ} \mathrm{C}$. Já na região 3 (pontos verdes, Fig. 3), tem-se mínima temperatura média diária de $5^{\circ} \mathrm{C}$ e máxima de $37,5^{\circ} \mathrm{C}$ com uma mediana de $21^{\circ} \mathrm{C}$. Em relação à região 4 (pontos amarelos, Fig. 3), notamos que a mínima temperatura média diária foi de $6^{\circ} \mathrm{C}$ e a máxima de $31,5^{\circ} \mathrm{C}$, e a mediana de $18^{\circ} \mathrm{C}$. A região 5 (pontos roxos, Fig. 3) apresentou mínima temperatura média diária de $10^{\circ} \mathrm{C}$ e máxima de $36^{\circ} \mathrm{C}$ com mediana de $21^{\circ} \mathrm{C}$. Quanto à região 6 (pontos cinzas, Fig. 3), nota-se que a mínima temperatura média diária foi de $12^{\circ} \mathrm{C}$ e a máxima de $37,5^{\circ} \mathrm{C}$ aproximadamente, e mediana de $23^{\circ} \mathrm{C}$.

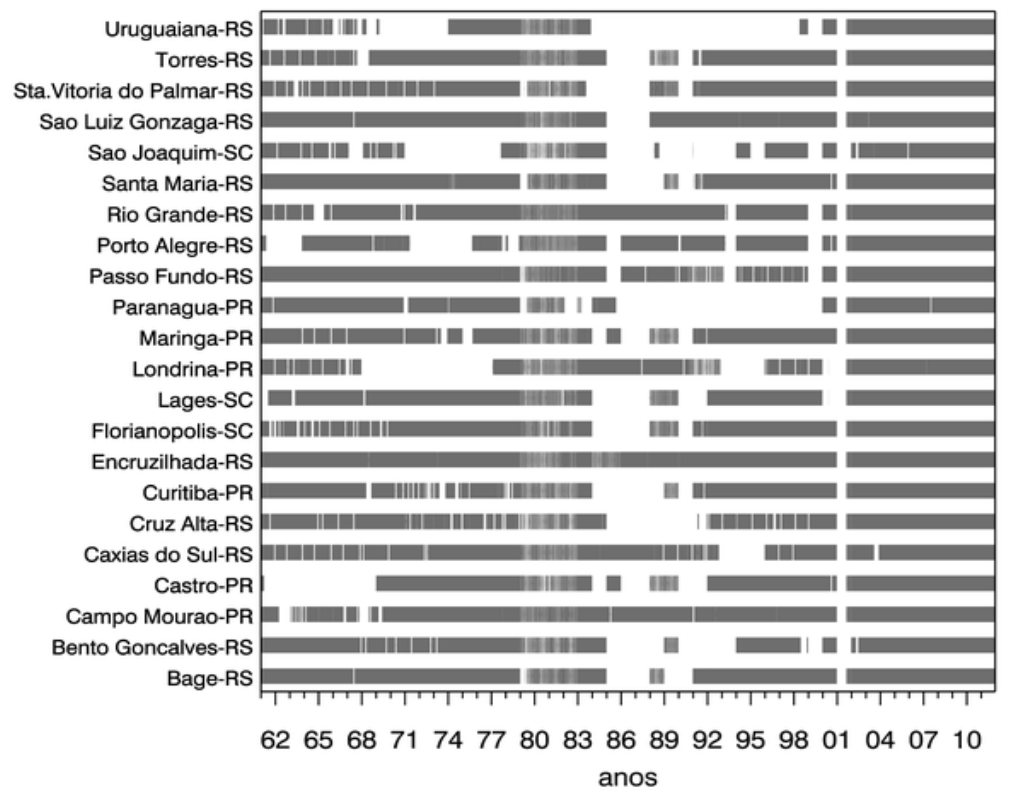

Figura 1. Disponibilidade dos dados diários de temperatura do ar entre 1961-2011 das estações do INMET utilizadas neste estudo. 


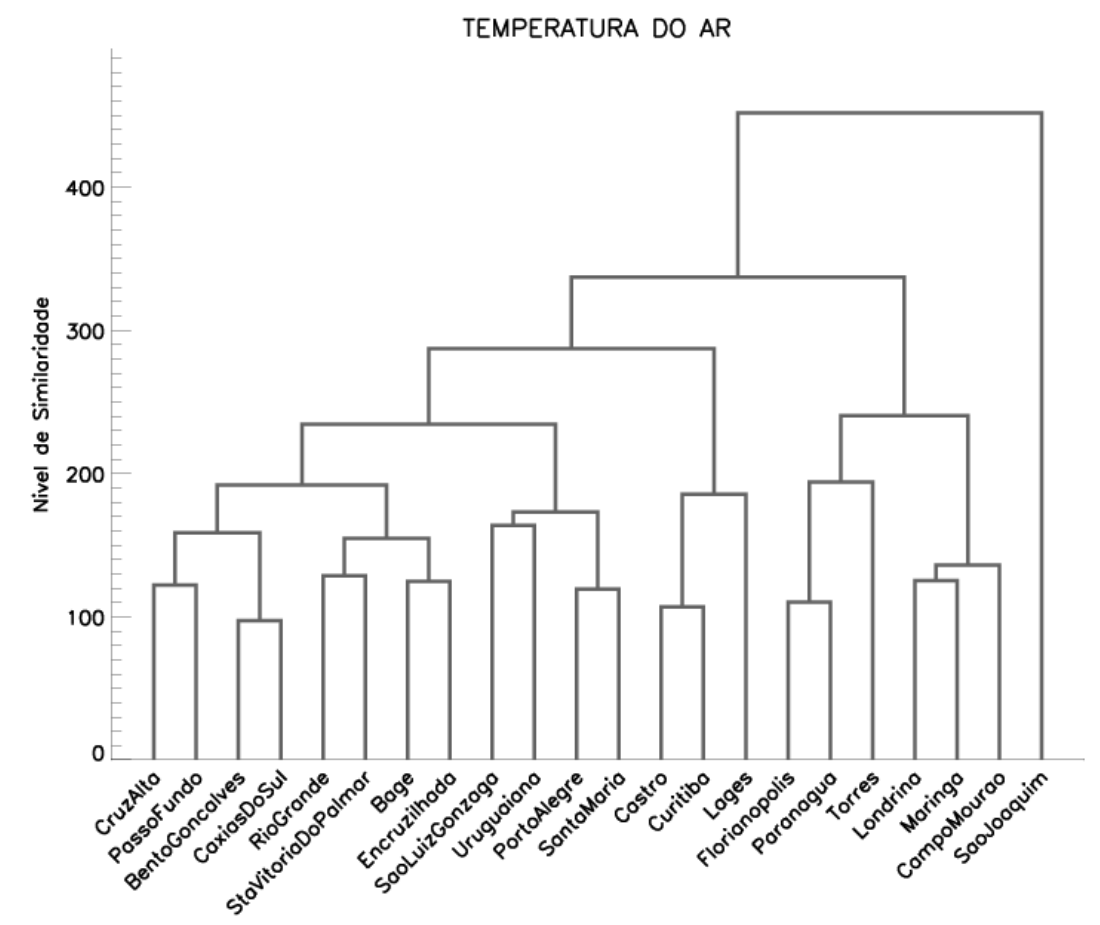

Figura 2. Dendrograma da análise de agrupamento da temperatura média do ar nas estações do INMET no Sul do Brasil entre 1961-2011.

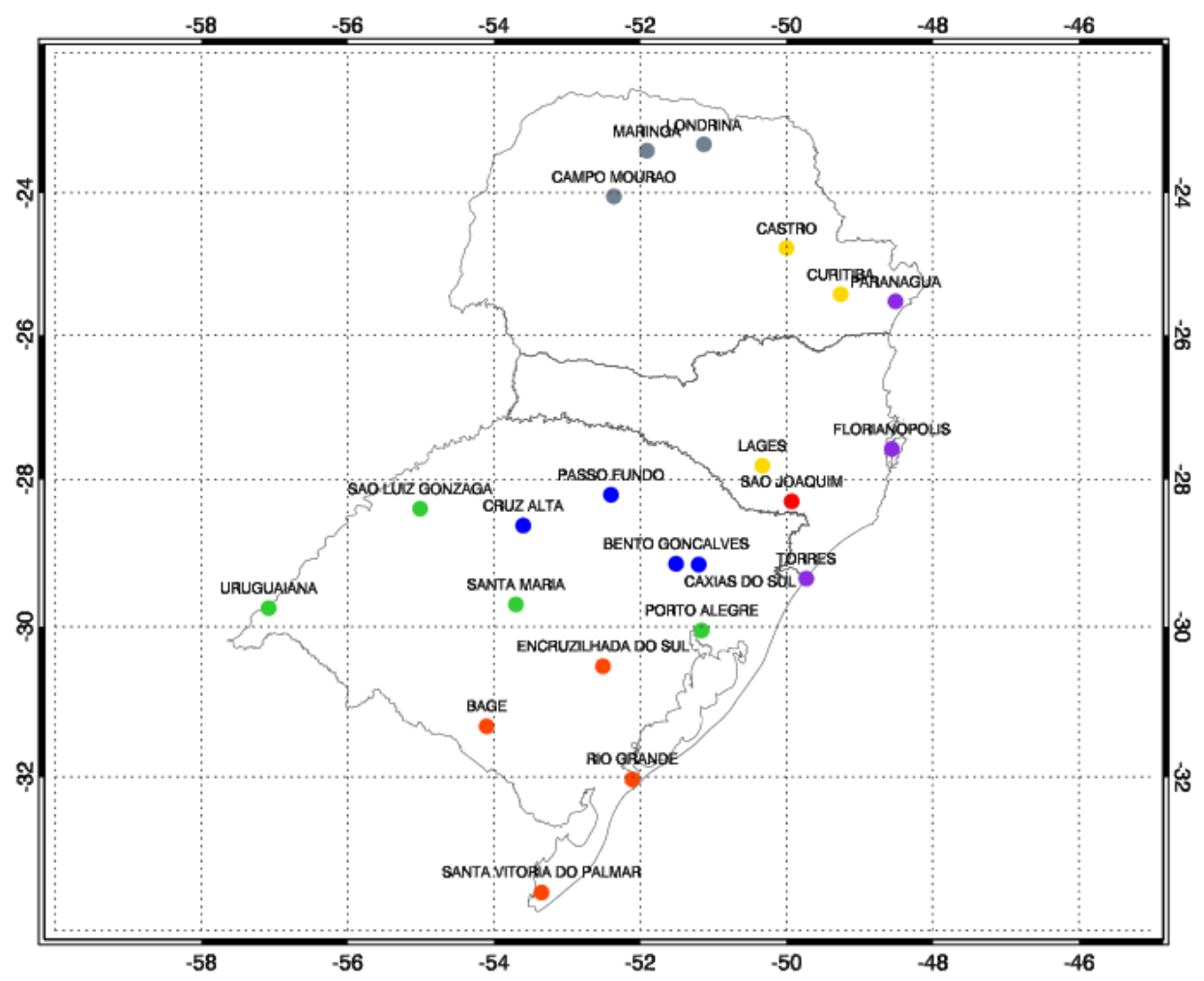

Figura 3. Regiões homogêneas da temperatura média do ar entre 1961-2011 na Região Sul. 


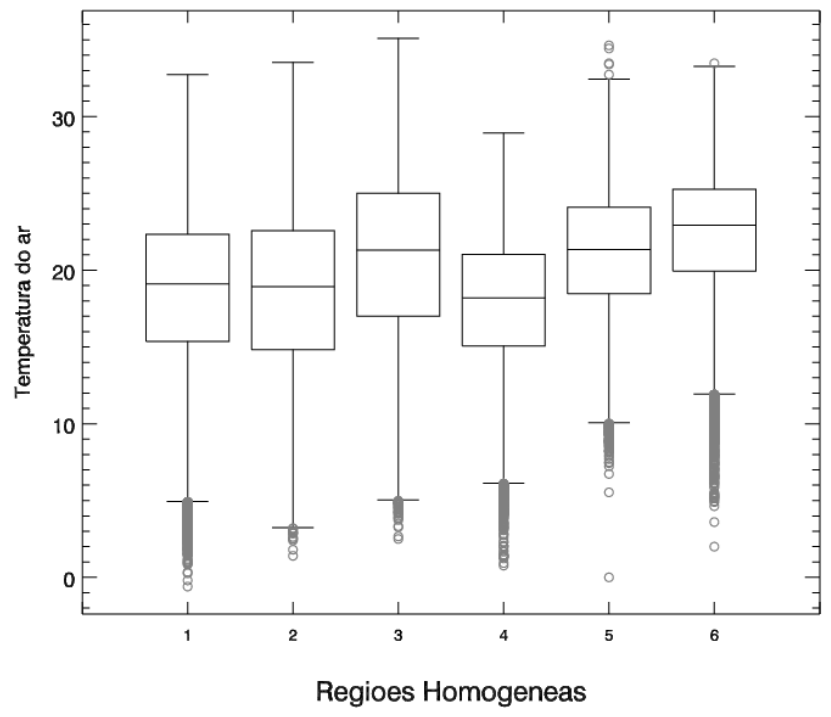

Figura 4. Box plot das regiões homogêneas da temperatura média do ar na região Sul entre 1961-2011.

\section{CONCLUSÕES}

As regiões homogêneas 1,3 e 4 possuem comportamento parecido em relação à mínima temperatura média diária. Em se tratando da máxima temperatura média diária, as regiões 3 , 5 e 6 apresentam semelhanças. No que diz respeito à mediana, há pouca variação de uma região para outra. As regiões 4, 5 e 6 possuem uma amplitude térmica semelhante, em torno de $26^{\circ} \mathrm{C}$. Já nas regiões 1,2 e 3 a amplitude térmica é maior, por volta de $30^{\circ} \mathrm{C}$.

\section{REFERÊNCIAS}

ARAÚJO, S. M. Estudo da variabilidade climática em regiões homogêneas de temperaturas médias do ar no Rio Grande do Sul. 2005. 54 f. Dissertação (Mestrado em Meteorologia)-Faculdade de Meteorologia, Universidade Federal de Pelotas, Pelotas, 2005.

FILHO, T. K., ASSAD, E. D., LIMA, P. R. S. R. Regiões pluviometricamente homogêneas no Brasil; Pesquisa agropecuária brasileira, Brasília, v.40, n.4, Abril 2005.

IBGE, Levantamento Sistemático da Produção Agrícola; Rio de Janeiro, v.23, n.09, p.1-80, Setembro 2010.

IBGE. Rebanho bovino brasileiro ultrapassa os 200 milhões e se mantém como o maior do mundo. 2005. Disponível em:

<http://saladeimprensa.ibge.gov.br/noticias?view=noticia\&id=1\&busca=1\&idnoticia=499>. Acesso em: 05 set. 2013.

MACHADO, J. P., BLANK, D. M. P., ZONTA, J. H., JUSTINO, F. B. Comportamento da precipitação e da temperatura no Rio Grande do Sul baseado na análise de agrupamento; Revista Ciência e Natura, Santa Maria, UFSM, 2010.

WILKS, D. S. Statistical Methods in the Atmospheric Sciences. 2. ed. Estados Unidos da América: Elsevier, 2006. 